\title{
“DESMALLARMANDO": A IRREVERÊNCIA POÉTICA DE ANGÉLICA FREITAS
}

\section{“DISMALLARMANING": ANGÉLICA FREITAS' POETIC IRREVERENCE}

\author{
Diana Junkes Bueno Martha \\ $\mathrm{UFSCAR}^{1}$ \\ dijunkes@gmail.com \\ "eu quero é queimar Mallarmé com carvão brasileiro",2
}

\begin{abstract}
Resumo:
O objetivo deste artigo é apresentar algumas reflexões sobre o diálogo com a tradição que Angélica Freitas sistematicamente estabelece em sua obra, em especial, em Rilke Shake (2006/2007). Para tanto, propõe-se uma análise do poema "estatuto do desmallarmento", na qual procura-se evidenciar o riso e o chiste como mecanismos de leitura e devoração crítica da tradição. Como contraponto, apresenta-se o poema de Augusto de Campos, Tvgrama 1 - Tombeau de Mallarmé, misto de riso e melancolia, como também Provisão poética para dias difíceis de Marcos Siscar.
\end{abstract}

Palavras-chave: Mallarmé, Angélica Freitas, Augusto de Campos, Riso.

\begin{abstract}
:
The aim of this paper is to present some considerations on the dialogue with canon that Brazilian contemporary poet Angélica Freitas develops in her work Rilke Shake (2006/07). In order to do so, we propose a reading of the poem "estatuto do desmallarmento in which we pinpoint the laugher and the wit as reading procedures chosen to devour critically the tradition. As counterpoint we present Augusto de Campos poem Tvgrama 1 - Tombeau de Mallarmé, mixture of laugher and melancholy and Provisão poética para dias difíceis by Marcos Siscar.
\end{abstract}

Keywords: Mallarmé, Angélica Freitas, Augusto de Campos, Laugher.

Recibido: 2/11/2016

Aceptado: 30/11/2016

\footnotetext{
${ }^{1}$ Doutora em Estudos Literários pela UNESP/Araraquara. Foi Visiting Scholar da University of Illinois e da Yale University. Atualmente, é professora adjunta do Departamento de Letras e coordenadora do Programa de Pós-Graduação em Estudos Literários da Universidade Federal de São Carlos. Líder do Grupo de Estudos de Poesia e Cultura/GEPOC/ CNPq (dijunkes@gmail.com). Lattes: http://lattes.cnpq.br/1857520068239671 .

${ }^{2}$ Esta frase foi recolhida de uma discussão sobre poesia feita por um grupo de estudantes em fevereiro de 2015, a propósito da herança mallarmeana e do modo pelo qual Freitas mobiliza-a em sua poética, antropofagicamente. $\mathrm{O}$ autor é Lucas Câmara, a quem agradeço a generosidade de autorizar a citação.
} 


\section{A tradição entre risos}

As diferenças entre poetas e poéticas e a aparente ausência de projetos consistentes parecem apontar para um quadro desalentador, em que a poesia não tem mais o lugar de destaque que um dia mereceu nas letras brasileiras. Longe de querer enfrentar essa questão, até porque sua relevância talvez seja esgarçada, gostaria de pontuar alguns aspectos que me parecem fundamentais para a compreensão da lírica contemporânea brasileira. De um modo geral, pode-se afirmar que a poesia brasileira produzida dos anos 1980 até hoje apresenta, como linhas de força, algumas herdadas do modernismo, as seguintes frentes: a (i) leitura da tradição, (ii) relações entre poesia e cultura, (iii) violência e resistência e novas configurações da cidade, metalinguagem e lirismo. Tais frentes não são necessariamente excludentes e não é incomum que em um mesmo poeta, ou ainda, em um mesmo poema, várias delas se manifestem. Em muitos casos, essas frentes acabam por se tornar prisões da forma e do rigor e o que se tem, a partir dessa situação, é uma poesia que se afasta grandemente dos leitores. Como bem aponta Paulo Franchetti:

O lirismo contemporâneo brasileiro, no quadro herdado da tradição cabralina, é um lirismo culpado e regrado por tabus. Em poucos poetas e poucos poemas o eu se oferece, frágil, como algo que se julga no direito de existir e buscar a palavra. De poucos poetas nos perguntamos: quem é a pessoa que escreveu isto, que vê o mundo assim? Por que ele prefere falar desta maneira? E em quantos poetas encontramos algo frente a que pensamos: isso precisava ser dito - e precisava ser dito assim, em poesia? (Franchetti, 2012, [sp]).

Franchetti é arguto ao flagrar um dos maiores riscos a que a poesia brasileira contemporânea está sujeita. De outro lado, porém, buscando um cenário menos pessimista, talvez pudéssemos sustentar que muitos poetas estruturam seu discurso com liberdade inventiva e formal e alta carga poética, é o caso do mesmo Paulo Franchetti, cujos livros mais recentes Memória futura (2010) e Deste lugar (2012) atestam um exímio trabalho poético. Considerando as linhas de força acima mencionadas, é possível notar que uma se sobressai grandemente: a leitura da tradição. Esta permanece seja no apreço formal (Paulo Henriques Britto), nas experiências construtivas herdeiras do concretismo (Arnaldo Antunes), no tratamento da cidade como topos adverso (Fabio Weintraub) ou como o lugar em que o sujeito poético busca-se a si mesmo (Paulo 
Ferraz), e, ainda, na tensão formal do poema em prosa em que ingressam o discurso da tradição, elementos cotidianos, lirismo e metalinguagem (Marcos Siscar). Também Franchetti não é insensível a esse aspecto, mas o observa com certo ceticismo:

Do meu ponto de vista como leitor e crítico, esta é a tarefa premente da contemporaneidade brasileira: enfrentar o consenso, que se torna mais forte na medida mesma em que a tradição deixa de ser a alteridade que nos pressiona desde o passado e não funciona mais como substrato comum de referências e expectativas entre o leitor e o autor. Consenso esse que faz hoje da tradição algo inócuo, que apenas fornece material para glosa e piada, ou algo sagrado (e perdido), só recuperável pela celebração ritual - e que promove a negatividade facilitadora, que recusa no final das contas o confronto com as contradições do presente e a pujança de outras formas de produzir emoção e ideias (como a música, o cinema, o romance, entre outras), refugiando-se numa afirmação da distância que não consegue disfarçar a impotência. (Franchetti, 2012, [sp]).

De fato, impossível não concordar com Paulo Franchetti ao pensar que na medida em que a tradição deixa de ser alteridade, porque superadas as razões da incessante leitura da mesma empreendida na modernidade, seu lugar parece deslocar-se. Ler o passado não é mais urgente, afirmar uma voz nova, original, também não, entretanto, como atestam os poetas citados logo acima, essa leitura, em termos de reapropriação e diálogo continua a ser empreendida e de um modo bastante interessante, senão em todos, em alguns dos mais importantes poetas da geração 00. Ainda que pese o traço inócuo dessa tradição por força do seu deslocamento ou da recolocação de sua relevância como imagem de alteridade, a homenagem ritual nem sempre coincide com a recusa do presente, pelo contrário, muitas vezes é a renovação do diálogo que impõe não só a ressignificação do cânone, mas a afirmação de vozes poéticas que ao convocarem-no para o espaço do poema possibilitam ampla reflexão sobre uma poesia do agora (Campos, 1997). Também o movimento da glosa e da piada nem sempre pairam como non-sense e esvaziados de valor poético. A meu ver, Angélica Freitas é uma voz que mostra que a leitura da tradição ainda tem por onde ser dessacralizada, não para negar essa tradição, mas para, ao fim e ao cabo, aprender a conviver com ela, tornando-a, nos termos de Margel (2000), indene, e isso, ainda que seja paradoxal, não deixa de ter sua dose de gratidão (Derrida, 2005; Siscar, 2000). 
A poeta gaúcha Angélica Freitas ${ }^{3}$ já há algum tempo desperta o interesse da crítica. Seus três últimos trabalhos têm sido alvo de debate e discussão entre críticos literários. O primeiro deles, Rilke Shake, publicado em 2006, pela Editora 7 letras, e em 2007, pela Cosac \& Naify; Guadalupe, uma HQ ilustrada por Odyr, publicada em 2012 pela Quadrinhos na Cia, mergulha no universo feminino da protagonista que dá nome ao livro e mantém traços característicos de Freitas: o humor e a ironia; por fim, Um útero é do tamanho de um punho, de 2013, que recupera temáticas existentes em Rilke Shake, como o diálogo com a tradição, o mergulho no universo cotidiano da cultura de massa e da cultura pop, sempre em dicção que desafia o discurso erudito e canônico, além, claro, de poemas voltados para o universo feminino, não necessariamente feminista e calcado em discussões de gênero. A autora possui uma fortuna crítica bastante diversificada, que conta com dissertações e artigos acadêmicos ${ }^{4}$, publicações em blogs e sites voltados para poesia, além de suas próprias postagens em especial para Revista Modo de Usar \& Co., da qual é uma das editoras ${ }^{5}$.

Parece-me que é, justamente, a persistência de traços de um projeto poético ou de uma forma específica de lidar com o poético que vem impulsionando a leitura da poeta pela crítica acadêmica ou não. Ao fazer opção pelo riso e/ou ironia como porta-vozes de uma poesia extremamente competente, Freitas mostra que, de fato, a leveza, é uma das propostas para a literatura no próximo milênio (Escute; Toneto, 2013), como propôs Calvino e é por meio dessa leveza, que não deve ser confundida com falta de seriedade, que a poética freitiana impõe-se como uma das vozes mais interessantes da poesia brasileira contemporânea, seja porque retoma o poema piada e poema-blague de nosso modernismo; seja porque nela se reconhece um gesto antropofágico de leitura da tradição, em que se deglutem várias tendências ao mesmo tempo; seja porque ambos os movimentos, ao associarem-se a procedimentos irônicos, denunciam o mundo contemporâneo, os imperativos de gênero a que as mulheres ainda estão sujeitas e a herança da necessária e inevitável absorção do cânone pelo poeta contemporâneo.

\footnotetext{
${ }^{3}$ Ideias preliminares sobre a poética de Freitas foram desenvolvidas por mim em "Entre carrapichos e shakes: duas formas de dialogar com a tradição", publicado em Bonafim, Alexandre; Yokosawa, Solange. Poesia Brasileira Contemporânea \& Tradição. São Paulo: Nankin, 2015, p. 109-128.

${ }^{4}$ Uma rápida busca na Plataforma Lattes (www.cnpq.br), que dá acesso aos currículos dos pesquisadores brasileiros, por assunto, na base de mestres e doutores, realizada em $9 / 4 / 2015$, revela mais de 50 entradas para Angélica Freitas, como assunto, o que pode conter, evidentemente, algum viés. Refinando a busca tem-se 7 entradas para Rilke Shake e 7 entradas para Um útero é do tamanho de um punho.

${ }^{5}$ (http://revistamododeusar.blogspot.com.br).
} 
Em Rilke Shake (Freitas, 2006) o que se assiste é um processo de autoparodização da poesia elevada que se desdobra em ridicularização e rebaixamento dos grandes poetas do cânone, atendendo a um movimento de desconstrução e subversão dessa herança pela via do derrisório (Bakhtin, 1985), como o próprio título e vários dos poemas do livro indicam (Bittencout, 2014). Evidentemente, esse processo não é novo, Duchamp talvez tenha sido um dos primeiros a chocar o mundo das artes com sua famosa Monalisa:

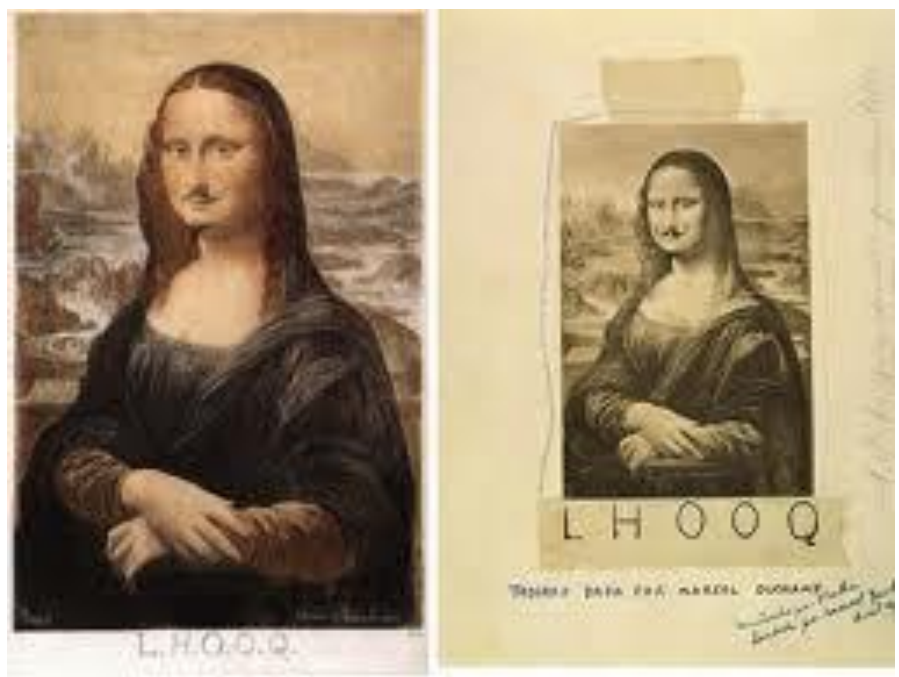

O ready-made de Duchamp, de 1919, aparta a obra de Da Vinci de sua realidade para fundar outra, em que pelo rebaixamento (“L.H.O.O.Q" - Ela tem fogo no $\mathrm{cu}$ ), temse a sensação de desconstrução (Martha, 2015); ao mesmo tempo, não deixa de ser uma forma de afirmação desse mesmo cânone já que a obra de Da Vinci sempre ecoará como um ruído de fundo, tornando-se não apenas pela subversão, evidentemente, mas também por causa dela, cada vez mais clássica (Calvino, 2005).

É possível pensar que nesse processo de paródia e riso, além da ironia, há boa dose se não de melancolia, de uma tristeza clown, que engendra o riso, mas revela, ao fazer isso, o desconcerto do mundo do artista que parodiza. Esse processo pode ser associado ao chiste freudiano, que se configura, em linhas gerais, pela emergência de um sintoma, ou da verdade do sujeito. O chiste é algo que escapa no discurso e, ao fazer isso, dá a ver, ou ainda, denuncia, pela alta carga de condensação que o caracteriza, o sujeito falante; ao mesmo tempo, por provocar o riso, desencadeia um alívio de tensões 
e viabiliza, em muitos casos, um movimento de sublimação. Não é o objetivo aqui pensar as categorias do cômico, do riso, do humor, por isso, sem insistir em diferenças, tomarei o estabelecido por Freud: o chiste refere-se a gracejos, piadas, trocadilhos e provoca o riso por meio de palavras e ideias. O cômico refere-se a eventos ou objetos lúdicos, gozados, alegres e envolve a percepção de algum tipo de contraste. E o humor refere-se à pessoa que dá pouca importância a seus infortúnios e está apta a ver seu lado engraçado (FREUD, 1996). Parece-me que todas essas instâncias ingressam em vários dos poemas de Freitas.

Se quiséssemos estabelecer uma linha histórica do tratamento do humor na poesia brasileira, como bem aponta Wilberth Salgueiro (2002), teríamos que retomar ao poeta barroco Gregório de Matos e a partir dele não seriam poucos os poetas que associaram humor e poesia em seus trabalhos. No caso de Freitas, a retomada do poema-piada e da blague oswaldianos é bastante evidente, mas notam-se as presenças de Drummond e evidentemente dos poetas marginais e poetas da geração de $80 / 90$, dentre os quais podese perceber a relação de Angélica com, entre outros, Leila Míccolis. Em todos esses casos, a associação do humor à poesia promove uma ruptura com os padrões estabelecidos, firmando, pelo ludismo transgressor, uma oposição ao senso comum.

Para Bergson (1983), o risível liga o riso ao atrito entre a maleabilidade e a organicidade que deveria existir na figura humana e a rigidez mecânica de comportamentos e gestos incompatíveis com a expectativa de flexibilidade da vida. $\mathrm{O}$ riso em Angélica é derrisório e afronta, justamente, a seriedade com que vários temas, entre os quais, a tradição, é tratada pelo poeta contemporâneo. Ao tornar risíveis os poetas do cânone em sua obra, Freitas não apenas desafia o imperativo "é preciso ler e reinventar a tradição", rebaixando, os poetas citados, como rebaixa também, por extensão, as leituras que são feitas desses poetas por poetas modernos e contemporâneos, ao mesmo tempo reforça e mantém vivos tais poetas, já que a outra face do rebaixamento é, como no caso da Mona Lisa de Duchamp, a inevitável homenagem. Desse modo, em alguma medida, os poemas de Freitas atuam, também, como ready-mades.

Por isso, engana-se quem pensa que a poeta é despreocupada e pouco compromissada com a poesia. A compreensão dos elementos cômicos na obra de Freitas pressupõe um leitor erudito, que perceba, na esteira do que propõe Propp (1976), que o riso é elevado, sofisticado, e que seja ainda leitor da tradição, afinal, como se sabe, o nexo entre o objeto cômico e a pessoa que ri não é obrigatório nem natural. Para haver 
riso, é preciso haver o reconhecimento dessas duas instâncias. Ao convocar a tradição e aspectos específicos desta mesma tradição, Freitas desafia a dicotomia seriedade $\mathrm{x}$ comicidade, mostrando que por meio do cômico uma profunda reflexão sobre o papel do poeta contemporâneo em relação à tradição pode ser empreendida. Para ampliar a perspectiva aqui proposta para a obra da poeta Angélica Freitas, proponho uma breve comparação entre poemas de diferentes poetas e um poema freitiano em que Mallarmé figura como ponto central.

\section{Os ris(c) os de Mallarmé}

Em um ensaio sobre Haroldo de Campos, Marcos Siscar aponta a importância de Mallarmé na construção da poesia haroldiana (Siscar, 2006), e fazendo uma ousada comparação, situa o poeta francês como "barqueiro de Haroldo", remetendo-se aí a um Mallarmé-Caronte. De fato, para atravessar o Letes em busca do encontro com a tradição e com vistas a reinventá-la, eu diria que não apenas Haroldo de Campos, mas vários poetas modernos e contemporâneos situam Mallarmé como grande mestre, desde Valéry. Se Um lance de dados era, para seu autor, em 1897, "nada ou quase uma arte", uma partitura (Mallarmé, 2002), uma aventura, para aqueles que vieram depois dele, o poema assume não apenas o papel de divisor de águas, mas torna-se um norte para onde passará a apontar a agulha da bússola da criação. Em outras palavras, Mallarmé torna-se um clássico, ou seja, nos termos de Ítalo Calvino (2005), o clássico é aquele texto que permanece sempre como ruído de fundo, ou, para nos valermos da comparação de Siscar, o guia da travessia.

Para ficarmos em alguns exemplos contemporâneos, cabe convocar aqui um conhecido poema de Augusto de Campos, "Tombeau para Mallarmé", da série “tvgrama”, de 1988, publicado em Despoesia de 1994, e o melancólico "Provisão poética para dias difíceis", de Marcos Siscar, publicado em O roubo do silêncio, de 2006.

O poema de Augusto representa de modo muito interessante toda a reflexão sobre a espacialidade gráfica, ao mesmo tempo que, em tom gris, afirma a inexistência 
de leitores de Mallarmé:

\begin{tabular}{|c|c|c|c|c|c|c|c|c|c|c|c|c|}
\hline $\mathbf{a}$ & h & $t$ & 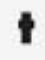 & $\uparrow$ & $\mathbf{m}$ & $\mathbf{a}$ & I & I & ๑ & $\mathbf{r}$ & $\mathbf{m}$ & é \\
\hline$\uparrow$ & 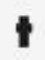 & $t$ & 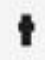 & $\uparrow$ & $\uparrow$ & 1 & $\uparrow$ & 1 & 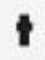 & $\uparrow$ & $\uparrow$ & $\uparrow$ \\
\hline $\mathbf{a}$ & C & $\mathbf{a}$ & $\mathbf{r}$ & n & e & é & † & $r$ & i & $\mathbf{s}$ & $\uparrow$ & e \\
\hline$\downarrow$ & 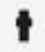 & $\uparrow$ & $\uparrow$ & $\downarrow$ & $\uparrow$ & $\uparrow$ & 1 & $\uparrow$ & $t$ & $\uparrow$ & 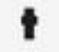 & $\uparrow$ \\
\hline e & $\mathbf{n}$ & i & n & g & $\mathbf{u}$ & é & $\mathbf{m}$ & $\$$ & 1 & e & I & $\hat{\mathbf{e}}$ \\
\hline$\uparrow$ & 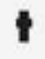 & $\boldsymbol{1}$ & 1 & $\uparrow$ & $t$ & $\uparrow$ & † & $\uparrow$ & $\uparrow$ & $\downarrow$ & $\uparrow$ & $\boldsymbol{\imath}$ \\
\hline$\uparrow$ & $\mathbf{v}$ & d & • & $\uparrow$ & $\uparrow$ & $\uparrow$ & e & $\mathbf{x}$ & $\mathbf{i}$ & $\mathbf{s}$ & $\uparrow$ & e \\
\hline$\uparrow$ & $\uparrow$ & $\uparrow$ & $\uparrow$ & $\downarrow$ & $\uparrow$ & $\uparrow$ & $\uparrow$ & $\uparrow$ & 1 & $\uparrow$ & 1 & $\uparrow$ \\
\hline $\mathbf{P}$ & $\mathbf{r}$ & a & $\mathbf{a}$ & C & a & b & $\mathbf{a}$ & $\mathbf{r}$ & e & $\mathbf{m}$ & $\uparrow$ & $\mathbf{v}$ \\
\hline
\end{tabular}

(Campos, 1994, p.109)

Evidentemente, há uma dose de humor que provoca o riso ao lermos "tv" ao final do poema; também há ironia ao retomar o discurso bíblico: "Vigiai e orai para que não entreis em tentação; na verdade, o espírito está pronto, mas a carne é fraca" (MATEUS, 26: 41). No poema, a carne não é fraca, mas é triste, mergulhadas que estão as pessoas no universo da TV que ao fim e ao cabo é o que existe, ou onde a vida, por fim, se resume: "tudo existe para acabar em tv". Não se trata de uma crítica moralista ou de ethos politicamente correto contra a TV, o que poderia fazer pensar que a carne é fraca e se rende à tv, mas da constatação de que ninguém lê Mallarmé - talvez por isso o entristecimento da carne, para além do entristecimento da alma. Ao fim, TV e Mallarmé rimam como que para corroborar a troca da perspectiva mallarmeana pela televisiva. $\mathrm{O}$ som da tv percorre todo o poema, cujos espaços que deveriam estar supostamente em branco são preenchidos pelo $t$ da tv, ou seja, o silêncio, o branco da página, o desafio do poema, os intervalos da leitura não existem porque as lacunas são preenchidas pelo invasivo e incômodo $\mathrm{tttttttttt}^{6}$. Desse modo, tensionando humor e melancolia, o poema concretista de Augusto não só afirma a herança mallarmeana, em termos formais, como aponta para o fato de que a força dessa herança parece estar ameaçada de dissipação.

\footnotetext{
${ }^{6}$ Vários dos poemas de Augusto de Campos são feitos para sonorização. A leitura do poema aqui mencionado pode ser assistida em: https://www.youtube.com/watch?v=omecBkn9UB0
} 
Em "Provisão poética para dias difíceis", o tom é mais melancólico ainda, todavia o eu-poético parece ter conseguido definir os termos da devoração da tradição que lhe interessam, ou seja, os elementos dos quais vale a pena se apropriar em cada poética dos diferentes poetas mencionados no poema. Não se trata mais de uma constatação irônica sobre a leitura de Mallarmé, mas do fato de que para além do peso da tradição, busca-se simplicidade, recurso tantas vezes difícil de ser atingido, em projetos poéticos complexos, mergulhados na leitura do cânone. Há também uma mudança de tom muito interessante: o eu-poético do poema não busca apenas as poéticas, os poetas, mas busca aquilo que de suas poéticas reúne, justamente, o caráter do simples: a maçã, os deslimites da tipografia, as asas, o mar, a leveza de cada um dos poetas citados como se não houvesse mais lance de dados porque os dados já foram lançados, não há mais acaso, mas apenas o baú de guardados com os elementos de provisão (poética) para dias difíceis. Vejamos o poema:

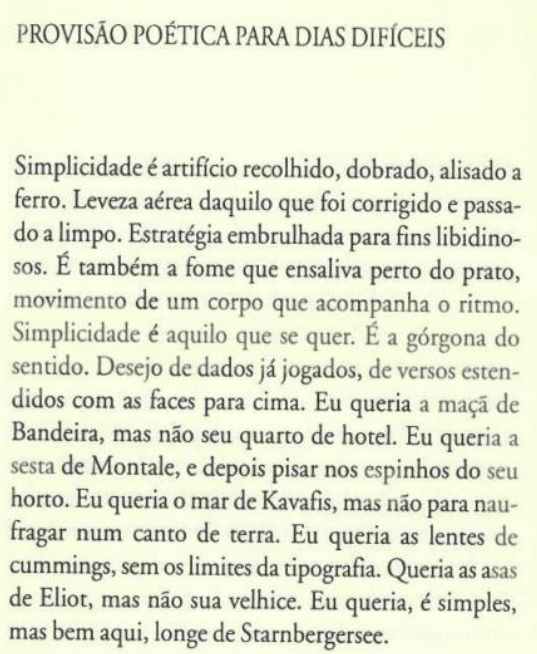

(Siscar, 2006, p. 66)

Já em movimento aparentemente menos profundo e mais inócuo, para usarmos aqui o termo de Paulo Franchetti citado acima, Angélica Freitas retoma a herança mallarmeana por meio do riso, da ironia e da aparente desconstrução de Mallarmé, seguindo uma trajetória, no poema em questão, semelhante àquela proposta por Duchamp para "reler" a Mona Lisa. O discurso do poema torna Mallarmé derrisório, rebaixa a importância de sua obra, ao revelar uma opção pelo chiste e pelo riso: 
estatuto do desmallarmento

minha senhora, tem um mallarmé em casa? você sabe quantas pessoas morrem por ano em acidentes com o mallarmé?

estamos organizando uma consulta popular para banir de vez o mallarmé dos nossos lares as seleções do reader's digest fornecerão

contêineres onde embarcaremos os exemplares no porto de santos, de volta para frança, seja patriota, entregue seu mallarmé, olê. (Freitas, 2006, p.53)

No título, a ironia e o humor fazem-se presentes, afinal, "estatuto do desmallarmento" remete a estatuto do desarmamento, não apenas em termos paronomásticos, mas porque desarmamento acaba por guardar certa relação anagramática com “desmallarmento". Desse modo, Mallarmé é uma arma. A polissemia de arma aqui é interessantíssima: arma da poesia moderna contra o discurso linear, arma do poeta que se inspira em Mallarmé, arma de Mallarmé que, ao invocar releituras dos poetas contemporâneos, acaba por impor a eles um modo mallarmaico de ser e estar na poesia e arma, por fim, porque causa acidentes - entra aqui a força do acaso que nem um lance de dados é capaz de abolir (Mallarmé, 2002). Desse modo anuncia-se o que segue pelo resto do texto, a começar, justamente, pela questão do acaso indomável e dos riscos impostos por ele.

A primeira estrofe, não por acaso, começa com um alexandrino, o verso clássico, por excelência, da poesia francesa. O segundo verso dessa estrofe, se ignorado o hiato em pessoas mantém o mesmo número de sílabas. A estrofe encerra com um decassílabo. Ou seja, não parece casual que a autora vá falar de Mallarmé, do grande syntaxier, o ruptor dos versos, aquele que coloca o poema em crise de versos, usando o alexandrino. De fato, em seu famoso Crise de vers, centrando sua análise na novidade do verso livre, contraponto ao tradicional alexandrino francês, Mallarmé evoca a maestria do verso como força da poesia, mesmo quando em crise, ou seja, mesmo quando desafiador das formas mais tradicionais para adequar-se a novas exigências da forma a fim de dar conta de novos conteúdos; o verso é a base de praticamente todas as produções poéticas. Assim, na aparente falta de seriedade de Freitas, muitas vezes associada a ela devido ao humor, há, parece-me, uma reflexão interessante sobre o peso da tradição. O restante do poema segue em versos de catorze sílabas, em sua maioria, fazendo ecoar o metro do 
alexandrino arcaico, apesar de não haver regularidade nos acentos, com o qual o alexandrino de doze sílabas rompe.

As considerações de Tomachevski (1989) sobre o verso são interessantes porque associam à discussão a questão do metro. Para ele, o metro representa a norma à qual a língua poética obedece. É o metro o fator distintivo, pois o ritmo também ocorre na prosa e na fala cotidiana. Assim, a organização do metro no interior do verso gera uma especificidade ao texto poético. Para Tomachevski (1989), os versos são períodos discursivos equipotenciais que nos dão, por sua sucessão, a impressão de uma repetição organizada de séries semelhantes. O metro tem a função de facilitar a comparação e contribui para a organização rítmica do poema. Além disso, o metro acompanha sempre a leitura e a percepção dos versos, seja como escansão silenciosa, seja como representações motrizes, dentre as quais pode-se destacar a rima como fator organizador que ajuda o ouvido a perceber a decomposição métrica da linguagem poética.

Por fim, Tomachevski (1989) nota que no caso do verso livre, já por sua própria definição, uma violação dos metros tradicionais, cumpre observar outros aspectos que lhe garantam a regularidade em cada poema no qual ele se apresenta. Ou seja, como é o ritmo, como são as rimas, como são as imagens. No verso livre, para além do metro, o desafio do poeta é buscar outras normas que garantam a harmonia e inter-relação dos versos, no poema. Portanto, é de notar que não são ingênuas as opções de Freitas, seu poema em verso livre, tendendo a um "desafio" da métrica, mostra que, como em Mallarmé, os versos talvez estejam em crise, ainda que esta não seja, nem de longe, aquela deflagrada pelo célebre Um lance de dados, mas uma outra, que para se "vingar" de Mallarmé, flerta com o metro clássico.

Retomando o percurso das estrofes, nota-se de saída o tom coloquial, radicalmente coloquial: "minha senhora/ você”. Ainda: há um tom de conscientização no discurso do eu-poético que alerta a senhora sobre os perigos causados por Mallarmé, pois, como uma arma, ele mata muitas pessoas anualmente em virtude de acidentes. A ironia associada ao humor, ao rebaixamento do grande poeta prossegue na segunda estrofe. A consulta popular (ou seja, para o povo, para o senso comum) indica que é preciso desarmar o Brasil de Mallarmé; como é afirmado na última estrofe, é preciso ser patriota e devolver o Mallarmé para a França. Apelando para um discurso que beira, ironicamente, o conservadorismo ("banir mallarmé de nossos lares"), ou eu-poético apela para a senhora, para a "zeladora da paz familiar", para que contribua enviando os 
exemplares de navio para seu país de origem, como se fosse o senso comum que lesse Mallarmé, mas este, já o sabemos, tem a carne triste e vive a ver TV.

O procedimento desconstrutor ainda é notado na menção ao Reader's Digest mais banalização impossível -, que se encarregará de levar Mallarmé para a França. E por quê? Porque é preciso que tudo exista para acabar em TV, ou seja, o perigo de Mallarmé está, justamente, em sua grandeza, na mudança que promove. Se aceitarmos esta, entre tantas outras possibilidades de leitura que o poema sugere, o tom de Freitas beira também a melancolia, rebaixa Mallarmé de um lado, mas isso é só um estratagema para demonstrar o respeito do eu-poético por ele, ou a gratidão, nos termos derridianos mencionados no início deste artigo. O último verso, "seja patriota, entregue seu mallarmé, olê", ao conclamar certo ufanismo barato, em meio ao riso provocado pelo olê das touradas (não se sabe se quem dá o olê é, afinal, o Mallarmé) reitera, ao fim e ao cabo, o desejo dos dados já lançados do poema siscariano: o que se quer é ser simples, mas se a tradição ainda é uma questão, como fazer isso?

\section{Considerações Finais}

A resposta a esta questão, a meu ver, no caso de Freitas, vem pela via do riso, do humor, da ironia, da irreverência. Tais aspectos dão ao seu projeto uma carga de leveza e e multiplicidade, ambos entendidos aqui da perspectiva defendida por Calvino em suas Seis propostas para o próximo milênio. Dessa forma, valendo-se da lição oswaldiana, abocanhando o tom deliberadamente irreverente dos marginais, Freitas promove algo além: um rilke shake em que não apenas Rilke, Blake, Pound, Mariane Moore, mas também Gertrude Stein, Lou Salomé, Mallarmé, Drummond e tantos outros são deglutidos pelo humor que disfarça (ou não disfarça para os leitores atentos) a erudição da poeta, a instigante proposta desse livro, em que latentemente pulsa uma das mais fortes linhas de força da poesia brasileira contemporânea: a leitura da tradição reinventada de modo vigoroso e inteligente, dando voz e vez a um projeto que permanece em Um útero é do tamanho de um punho associando aí uma instigante reflexão sobre o feminino. Nesse livro, Freitas também faz um shake dos discursos feministas em oposição à misoginia e centra a leveza e a multiplicidade que lhe são características, associadas à ironia, ao esforço de desconstruir também discursos facilmente rotuláveis, buscando, pela luta que o punho representa, novas formas de enfrentamento dessa questão. $\mathrm{O}$ diálogo com a tradição permanece, em moldes semelhantes, porém mais diluído, dando lugar a outras frentes que não se opõem 
àquelas de Rilke Shake, como muitos poderiam defender, mas que o continuam na medida em que se sofistica a voz da poeta, seu estilo, suas opções formais e a organicidade da obra irreverente, sim, como umas das melhores tradições de nossa poesia e, como essa tradição, de alta qualidade.

\section{Bibliografía}

Bakhtin, Mikail. "Epos e Romance" (sobre a metodologia do estudo do romance). Questões de literatura e estética: a teoria do romance. São Paulo: Hucitec, 1985. Impreso.

Bíblia Sagrada. Evangelho Segundo São Mateus. Acesso em 11/4/2015. $<$ www.bibliaonline.com.br/acf/mt/26>

Camargo, Goiandira F. O. "Subjetividade e experiência na leitura da poesia lírica brasileira contemporânea". Célia Pedrosa y, Ida Alves. Subjetividades em devir: estudos de poesia moderna e contemporânea. Rio de Janeiro: Ed.7 letras, 2008. 99-107. Impreso.

Campos, Augusto de. Despoesia. São Paulo: Perspectiva, 1994. Impreso.

--------.TVgrama. Disponível em

$<$ : https://www.youtube.com/watch?v=omecBkn9UB0>

Campos, Haroldo de. "Do verso à constelação. Poesia e modernidade. O poema pósUtópico". H. Campos. O arco íris branco. Rio de Janeiro: Imago, 1997. Impreso.

Calvino, Italo. Por que ler os clássicos? São Paulo: Companhia das Letras, 2005.Impreso.

---------. Seis propostas para o próximo milênio. São Paulo: Companhia das Letras, 2006. Impreso.

Derrida, Jacques. "Fidelidade a Mais de Um: Merecer Herdar onde a Genealogia Falta.” P. Ottoni. Tradução Manifesta: Double Bind e Acontecimento. São Paulo/ Campinas: Edusp/ Editora Unicamp, 2005, 167-198. Impreso.

Duchamp, Marcel. L.O.O.Q. Nova Iorque, 1919. Acesso em 12/4/2015. < www.marcelduchamp.net >

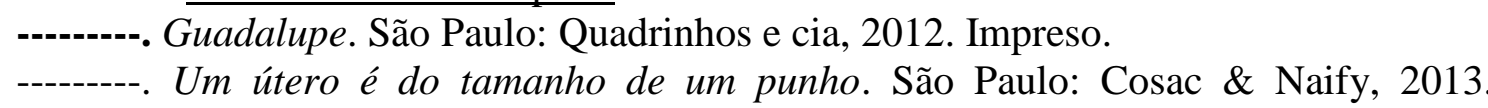
Impreso.

--------. Revista Modo de usar em co. Acesso em 12/4/2015. 〈www.revistamododeusar.blogspot.com $>$

Escute, João Paulo; Toneto, D. J. M. "Um drink de tradição e novidade: considerações sobre Rilke Shake de Angélica Freitas. Signótica 25. 1. (2013): 51-67. Impreso.

Freitas, Angélica. Rilke Shake. Rio de Janeiro: Ed. 7 letras, 2006, Coleção Ás de Colete. Cosac \& Naify, 2007. Impreso.

Freud, S. "Recordar, repetir e elaborar: novas recomendações sobre a técnica da Psicanálise" II. Edição Standard Brasileira das Obras Psicológicas Completas de Sigmund Freud [ESB]. Rio de Janeiro: Imago, 1996, vol. XII, 163-171. Impreso. "O chiste e sua relação com o inconsciente". Edição Standard Brasileira das Obras Psicológicas Completas de Sigmund Freud [ESB]. Rio de Janeiro: Imago, 1996, vol. VIII. 1-73. Impreso. 
Junkes Bueno, Martha, Diana. Entre carrapichos e shakes: duas formas de dialogar com a tradição", publicado em Bonafim, Alexandre; Yokosawa, Solange. Poesia Brasileira Contemporânea \& Tradição. São Paulo: Nankin, 2015. 109-128. Impreso.

Margel, Serge. "As denominações órficas da sobrevivência” Nascimento, E; Glenadel, P. Em torno de Jacques Derrida. Rio de Janeiro: CNPq/ 7 Letras, 2000, 203-230. Impreso.

Salgueiro, W. C. F.. Forças \& formas: aspectos da poesia brasileira contemporânea (dos anos 70 aos 90) . 1. ed. Vitória: Edufes, 2002. v. 1. 270. Impreso.

Siscar, M. A. "Paixão Ingrata". Nascimento, E. Gelnadel, P. Em Torno de Jacques Derrida. Rio de Janeiro: CNPq/ Ed.7 Letras, 2000. 160-187. Impreso. -." Estrelas Extremas: sobre a poesia de Haroldo de Campos". M.L.O. Fernandes, et. al. Estrelas Extremas: ensaios sobre poesia e poetas. Araraquara: Laboratório Editorial da FCL, 2006. Impreso. O roubo do silêncio. Rio de Janeiro: Ed. 7 letras, 2006. Impreso.

Tomachevski, B. "Sobre o verso". Todorov, T. (apresentação)Teoria da Literatura: Os Formalistas Russos. Lisboa: Edições, 1989. 70. Impreso. 